\title{
Yeast BUD5, Encoding a Putative GDP-GTP Exchange Factor, Is Necessary for Bud Site Selection and Interacts with Bud Formation Gene BEM1
}

\author{
John Chant, ${ }^{\star}+$ Kathleen Corrado, $\ddagger$ \\ John R. Pringle, $\ddagger$ and Ira Herskowitz* \\ *Programs in Genetics and Cell Biology \\ Department of Biochemistry and Biophysics \\ University of California, San Francisco \\ San Francisco, California 94143 \\ ‡Department of Biology \\ The University of Michigan \\ Ann Arbor, Michigan 48109-1048
}

\section{Summary}

Cells of the yeast S. cerevisiae choose bud sites in an axial or bipolar spatial pattern depending on their cell type. We have identified a gene, BUD5, that resembles BUD1 and BUD2 in being required for both patterns; bud5 ${ }^{-}$mutants also exhibit random budding in all cell types. The BUD5 nucleotide sequence predicts a protein of $\mathbf{5 3 8}$ amino acids that has similarity to the S. cerevisiae CDC25 product, an activator of RAS proteins that catalyzes GDP-GTP exchange. Two potential targets of BUD5 are known: BUDt (RSR1) and CDC42, proteins involved in bud site selection and bud formation, respectively, that have extensive similarity to RAS. We also show that BUD5 interacts functionally with a gene, BEM1, that is required for bud formation. This interaction provides further support for the view that products involved in bud site selection guide the positioning of a complex necessary for bud formation.

\section{Introduction}

The yeast budding pattern provides an opportunity to study the molecular basis for a simple spatial pattern. Yeast cells choose budding sites on their cell surface in a genetically programmed manner: $a$ and $\alpha$ cells exhibit an axial pattern, whereas a/ $\alpha$ cells exhibit a bipolar pattern (see Chant and Herskowitz, 1991). Two groups of gene products have been identified that play roles in this process. CDC24, CDC42, and CDC43 are a group of essential genes (termed bud formation genes) that is required for restricting growth of the yeast cell surface to the budding site. In codc24, cdc42, and cdc43 mutants, growth occurs uniformly over the cell surface, and the actin cytoskeleton is disorganized (Sloat et al., 1981; Adams and Pringle, 1984; Adams et al., 1990). CDC42 codes for a RAS-related protein (Johnson and Pringle, 1990). CDC43 appears to code for an enzyme that may posttranslationally modify the CDC42 protein (Finegold et al., 1991).

The BUD genes, BUD1-BUD4, are involved in selection of the bud site. Mutants defective in these genes are viable and exhibit either a random or bipolar budding pattern in haploid cells. As described in the accompanying paper

† Present address: Department of Biology, The University of Michigan, Ann Arbor, Michigan 48109-1048.
(Chant and Herskowitz, 1991), BUD1 and BUD2 are required for both the axial and bipolar patterns, whereas $B U D 3$ and BUD4 are required only for the axial pattern. These observations suggest a morphogenetic pathway in which budding at random sites represents an entirely undirected pattern, the presence of BUD1 and BUD2 leads to a bipolar pattern, and the further action of BUD3 and BUD4 leads to an axial pattern.

We also show in the accompanying paper that BUD1 is identical to RSR1, a gene identified on the basis of its genetic interaction with $C D C 24$ : high copy number plasmids carrying BUD1 can partially suppress the growth defect of cdc24-ts mutants (Bender and Pringle, 1989). The sequence of BUD1 (RSR1) shows it to be another member of the RAS family. The ability of BUD1 (RSR1) to suppress a coc24-ts mutation indicates that the BUD1 and CDC24 proteins interact functionally and perhaps physically. These and other observations have led to the suggestion that the $B U D$ products may function by directing the placement of the products involved in bud formation (Chant and Herskowitz, 1991; Bender and Pringle, 1989).

In this report, we describe the identification of two new genes, BUD5 and BEM1, that are involved in bud site selection and bud formation, respectively. BUD5 is a nonessential gene that resembles BUD1 and BUD2 in that it is required to produce both the axial and bipolar patterns of bud site selection. BEM1 appears to be related to the CDC24 group of genes in that it is involved in polarizing the cytoskeleton and restricting cell surface growth to the chosen site. We show that BUD5 and BEM1 interact functionally, which lends support to the hypothesis that the BUD proteins function to position the CDC24 group of proteins within the cell (Bender and Pringle, 1989; Chant and Herskowitz, 1991). Finally, we show that the BUD5 product has similarity to the Saccharomyces cerevisiae CDC25 product, an activator of RAS that catalyzes guanine nucleotide exchange (Jones et al., 1991; see Levitzki, 1990). This similarity raises the possibility that BUD5 might act on the RAS-like proteins, BUD1/RSR1 or CDC42.

\section{Results}

\section{Identification of BUD5}

The BUD5 gene was identified in the course of examining mutants containing alterations of the mating-type locus (MAT), to see if any exhibited an altered budding pattern. We observed that haploid strains carrying certain deletions affecting the mating-type locus (Figure 1)-MATa-x8 MATa::CAN1, and MATa-x7-12-all exhibited a random budding pattern. Surprisingly, other mutants defective in three known products encoded by $M A T, \alpha 1$ (inactivated by

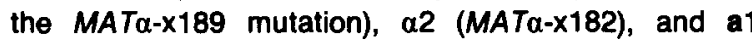
(MATa-x50), all exhibited wild-type behavior. The aberrant budding pattern exhibited by the deletion mutants was confirmed to be due to lesions at MAT in two ways. First, the mutant phenotype cosegregated with MAT in ten tetrads from each of two different crosses. Second, mutant 


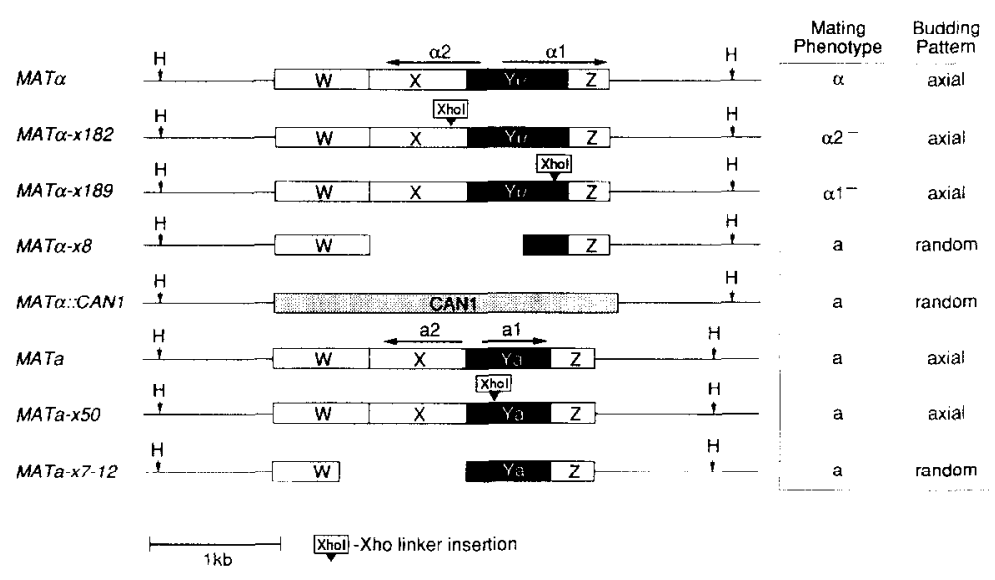

Figure 1. Effects of Various Mutations in the MAT Region on Budding Pattern

The diagram shows the mating-type locus (MAT) and flanking regions drawn to physical scale. MATa and MATa are nonhomologous in the regions indicated as $Y_{a}$ and $Y \alpha$, which are 642 and $747 \mathrm{bp}$, respectively (Astell et al., 1981). The $W, X, Y a$, and $Z$ regions are also found at the $H M L \alpha$ locus, and the $X, Y a$, and part of the $Z$ region are also found at the HMRa locus (Astell et al., 1981). The positions of the transcripts from MATa and MAT $\alpha$ are indicated by arrows. The positions of deletions or insertions of an Xhol linker are indicated (Tatchell et al., 1981; K. Tatchell, personal communication). MATa::CAN1 is a substitution of the indicated region by the segment containing CAN1. $H$ indicates HindIII sites. Mating phenotype: $\alpha$, mates as $\alpha$; a, mates as a (note that $\alpha 1^{-} \alpha 2^{-}$, a $1^{-}$, and a2 strains all exhibit the mating phenotype of an a cell; Strathern et al., 1981); $\alpha 1$, defective in mating and exhibits behavior of mat 1 mutant; $\alpha 2^{-}$, defective in mating and exhibits behavior of mata2 mutant. budding patterns were restored to the wild-type pattern by using mating-type interconversion to replace the mutant $M A T$ information with functional information from the silent $M A T \alpha$ locus, $H M L \alpha$ (see Experimental Procedures). These observations, in combination with those described above, indicated the existence of a gene in or near MAT that is necessary for axial budding.

We next determined whether the budding pattern defect of these mutants could be complemented by plasmids carrying MAT. Plasmid $p K 1$, which carries MAT $\alpha$ and approximately $10 \mathrm{~kb}$ to its left (see Figure 1), was introduced into the MATa::CAN1 and MATa-X8 mutants; it restored their budding behavior to the axial pattern. A plasmid (pJM9) that carried less DNA to the left of MAT $\alpha$ (only to the HindIII site; see Figure 1) did not restore axial budding to these mutants. These observations indicated that the gene necessary for bud site selection, designated $B U D 5$, extends from within the $W$ region leftward across the HindllI site.

To define more precisely the location of BUD5 relative to $M A T$, plasmid pK1 was mutagenized by transposon mutagenesis (see Experimental Procedures). Insertions of the $\gamma \delta(\operatorname{Tn} 1000)$ element into pK1 were isolated in Escherichia coli. The mutated plasmids were then transformed into a MATa::CAN1 recipient strain, and transformants were analyzed for axial or random budding and for mating ability (Figure 2A). Six insertions spanning a region of approximately $1.5 \mathrm{~kb}$ (insertions $8,6,20,33,16,39$, and 46) all resulted in plasmids that restored mating ability but not axial budding. These insertions appeared to inactivate BUD5 but not MATa. In contrast, insertions 60,48 , and 24 all resulted in plasmids that restored axial budding but not mating ability. These insertions thus inactivated MATa but left BUD5 intact. Insertion 67 did not disrupt either BUD5 or MATa; insertion 15 caused some reduction of BUD5 activity but had no effect on the ability to provide MATa functions. The behavior of these insertion mutants supported the hypothesis of a gene adjacent to and distinct from MAT $\alpha 2$ that is necessary for axial budding. A $2.7 \mathrm{~kb}$ segment of pK1 was subcloned into $Y C p 50$ to form plasmid pMIN1 (Figure 2A), which contains a functional BUD5 gene but not MAT $\alpha$, as shown by complementation of a MATa:: CAN1 mutant.

\section{The Nucleotide Sequence of BUD5}

Various subfragments of the BUD5 region were subcloned into $\mathrm{M} 13$, and the nucleotide sequences of both strands of a $1.6 \mathrm{~kb}$ segment that includes BUD5 were determined (see Experimental Procedures). Analysis of the sequence (Figure 3) revealed one open reading frame of 538 codons and no others greater than 50 codons having an ATG start. The position of this open reading frame corresponded to the region necessary for BUD5 complementing activity as identified by subcloning and transposon mutagenesis (Figure $2 A$ ). The open reading frame begins in the $W$ region of MAT, 307 nucleotides downstream of the stop codon for the $\alpha 2$ protein, and extends leftward into the region flanking MAT. The $W$ region of MAT, which is identical in MATa and MAT $\alpha$, encodes 189 amino acids; 349 amino acids are encoded to the left of W. The BUD5 coding sequence is thus completely nonoverlapping with products of the mating-type locus. Insertion 16 is probably within the open reading frame at $H M L$; insertions 39 and 46 may be upstream of the open reading frame. The information coding for the first 191 amino acids of BUD5 is present also at the silent MAT locus, HML (Astell et al., 1981). This open reading frame extends only two codons further due to a stop codon; it is not known whether this product is produced.

Analysis of the predicted BUD5 amino acid sequence revealed $20 \%$ identity over its last 400 amino acids with the carboxyl terminus of the $\mathrm{S}$. cerevisiae $C D C 25$ product (Camonis et al., 1986), an activator of RAS1 and RAS2 in the starvation-response pathway (Figure 4A). Some of these regions are also strongly conserved in other proteins 


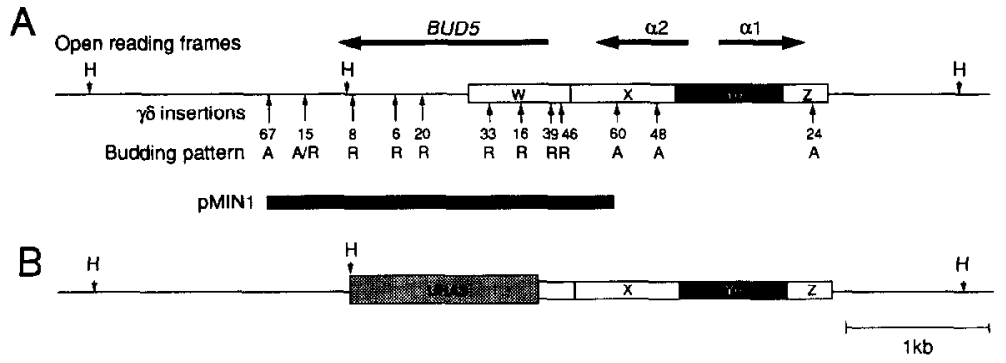

Figure 2. Location of BUD5 Relative to MAT (A) The diagram shows the positions of the BUD5, $\alpha 2$, and $\alpha 1$ open reading trames drawn to physical scale. The positions of insertions of the $\gamma \delta(\mathrm{Tn} 1000)$ element are indicated by arrows with associated numbers. Their phenotypes were determined by complementation of a MATa::CAN1 mutant (Figure 1) and are axial budding pattern $(A)$ and random budding pattern (A). Inserts 60,48 , and 24 are the only insertions that caused a defect in mating. The rectangle shows the DNA segment carried in plasmid pMIN1, which is the shortest tested fragment that can complement a bud5- mutation.

(B) The structure of the substitution mutation, bud5::URA3, in which URA3 replaces most of the BUD5 coding region.

that are thought to be functionally related to CDC25 (Figure 4B; see Discussion).

\section{The Phenotype of a BUD5 Null Mutant}

With the boundaries of the presumed BUD5 gene identified, it was possible to construct a null mutation in this gene to determine unequivocally its loss-of-function phenotype. A substitution mutation (bud5::URA3) was constructed in which 489 of the 538 codons of the BUD5 open reading frame were replaced with a segment carrying URA3 (Figure 2B). This construct was then used to produce a mutation in the chromosome by one-step gene replacement (Rothstein, 1983), as described in Experi- mental Procedures. The chromosomal gene was inactivated in a diploid a/a strain because we did not know whether BUD5 is an essential gene. The substitution event was confirmed by Southern blot hybridization (data not shown). Tetrads from the a/a BUD5+/bud5::URA3 diploid generally yielded four viable spores in which bud5::URA3 segregated 2:2, indicating that BUD5 is not essential for growth. The Ura' (Bud5-) segregants exhibited no alterations in mating phenotype, as measured by mating ability and $\alpha$ factor production, and did not show any defect in growth rate: colonies produced by bud5::URA3 spores were indistinguishable in size from their wild-type sister segregants. $\stackrel{1}{21} \stackrel{21}{41} \frac{61}{1}$ 81
CGCAAAATACATAAACAATCAACCCTCTCCTCAGACACTACTAAGATGTTTGTAACTGATAGATAATGTCCTCG 161
CCTACCTTCTTGACAAGACGACCTATTTCTAACCGCACGCTTCGCATCCAGGTCAAATCGTCTCAAGAAGAGTT 241
AACAAAATACATATCTCCACATCACAGACGTCCTTCTACAACAATtCATAAGTCACACACTGCCCTATAATGAC

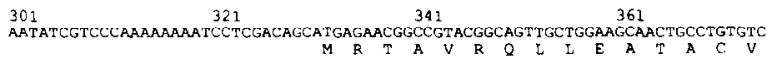

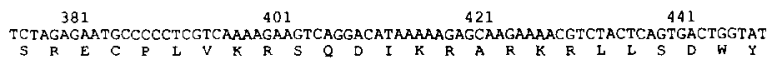

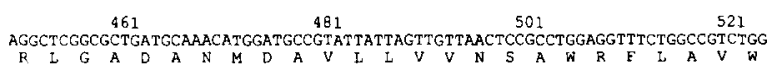

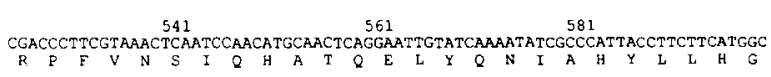

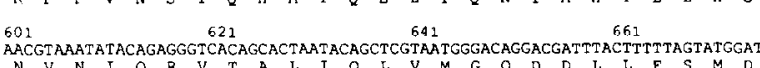
68107010721

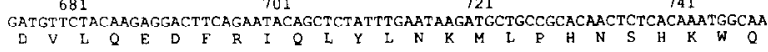
761
AAGCCATCCCCTTTGACTCCGCAACTTACTACTTAACTTCAGAGACTGGACAACTGACAATGCTCTCCTCCAA

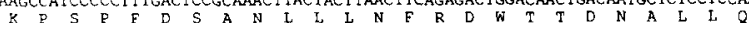

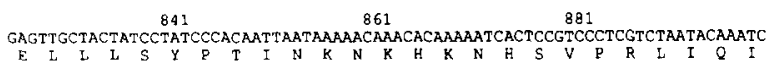

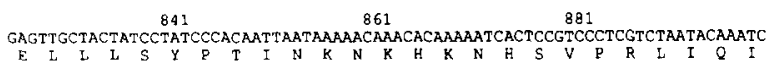

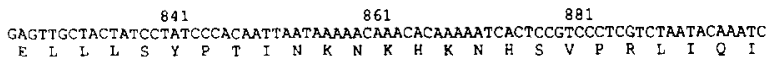
901 921 941 961 961

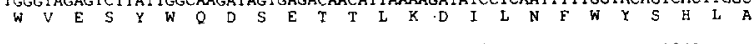

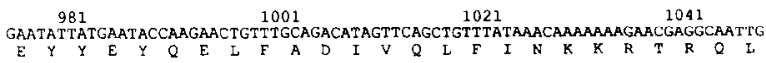

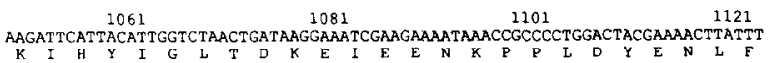

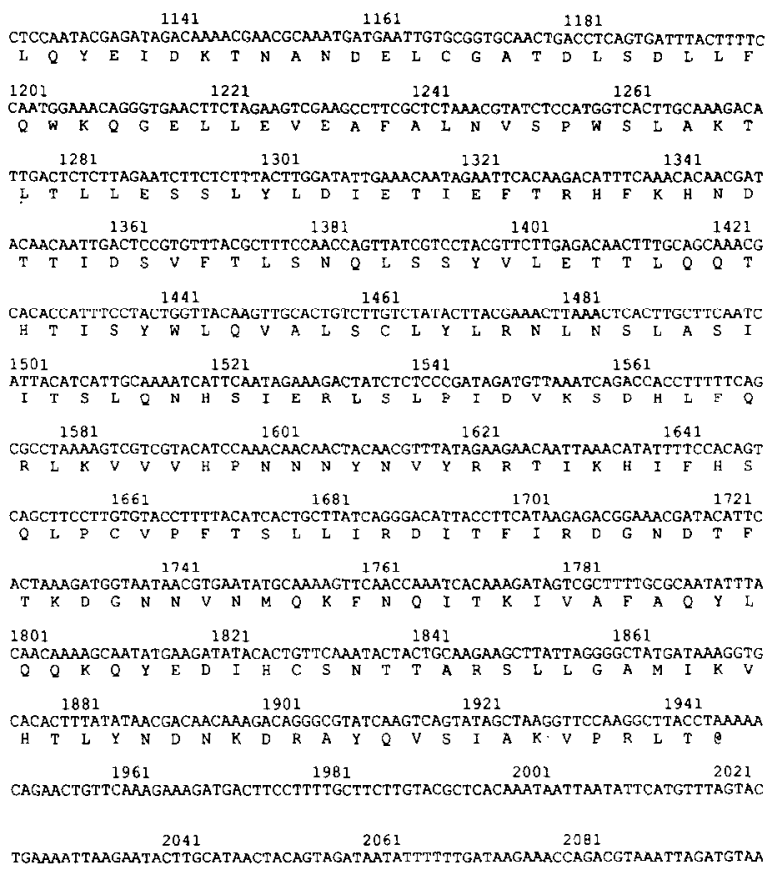

Figure 3. The Nucleotide Sequence of the BUD5 Region and the Predicted Amino Acid Sequence of the BUD5 Protein 
A

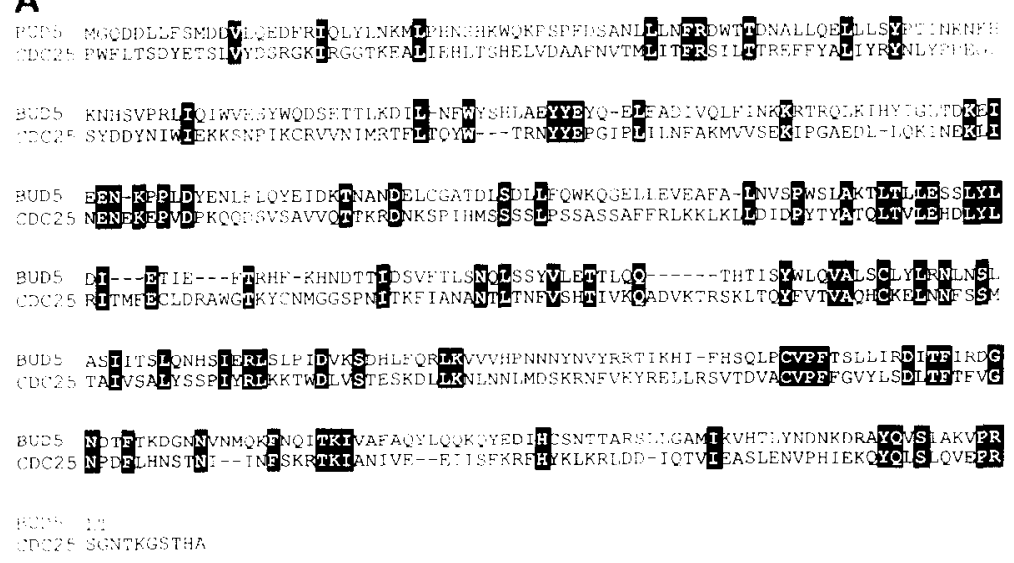

B

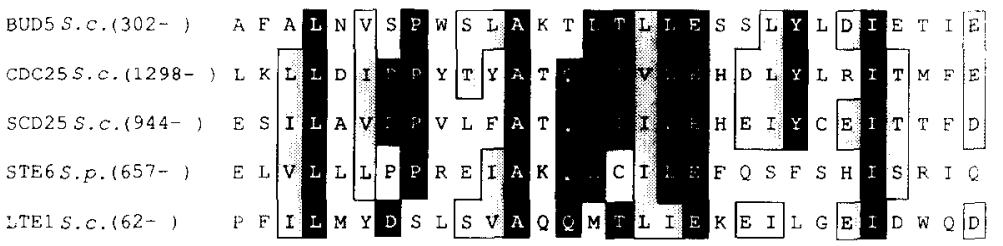

Figure 4. Sequence Similarities between the Predicted BUD5, CDC25, and Related Proteins (A) Comparison of BUD5 (residues 105 to end) and the carboxyl terminus of $S$. cerevisiae CDC25 (residues 1101 to end): identities are boxed. With the introduction of gaps as indicated, the two sequences are $20 \%$ identical over this segment $(85 / 420)$

(B) Comparison of BUD5 with other members of the S. cerevisiae CDC25 family. Identicat amino acids are boxed in black; similar amino acids are boxed using the following equivalences: $(K, R),(D, E),(N, Q),(S, T),(L, I, V)$ when at least three members are similar. S.c. S. cerevisiae; S.p., S. pombe. Sequence intormation is from the following: for CDC25, Camonis et al. (1986); for SCD25, Boy-Marcotte et al. (1989); for ste6, Hughes et al. (1990); and for LTE1, Wickner et al. (1987).

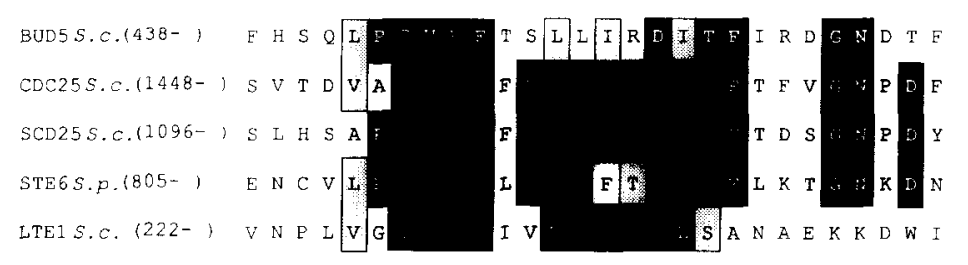

The budding pattern phenotypes of bud5::URA3 cells were evaluated both by examination of the budding patterns of microcolonies and by examination of the bud scars on individual cells. Figure 5 shows a quantitative analysis of budding pattern as seen in microcolonies. Wild-type $\alpha$ cells exhibited an axial pattern with high fidelity: $87 \%$ of microcolonies exhibited the class 4 pattern (Figure 5A). In contrast, wild-type a/ $\alpha$ cells exhibited the bipolar pattern: only $22 \%$ of the microcolonies were in class 4 , whereas approximately $70 \%$ were in classes 1 and 3 (Chant and Herskowitz, 1991). Bud site selection by the bud5::URA3 mutant (Figure 5B) was dramatically different from either of these wild-type patterns: the four possible classes of microcolonies were found in nearly equal frequencies, including class 2 , which is uncommon for either wild-type haploid or a/ $\alpha$ cells. $\chi^{2}$ analysis confirms that the bud5mutant differs from the a/a strain $(P<0.001$; Herskowitz, 1965). This behavior is similar to that of bud1 and bud2 mutants (Chant and Herskowitz, 1991). Analysis of the bud scars produced by bud5 mutants confirmed the randomness of the budding pattern (Figure 6): wild-type $\alpha$ Bud $^{+}$cells exhibited a row or cluster of scars; in contrast, bud scars of $\alpha$ Bud5 $5^{-}$cells were dispersed over the cell surface rather than being adjacent to each other. These observations are again similar to those made for bud1 and bud2 mutants (Bender and Pringle, 1989; Chant and Herskowitz, 1991).

To determine whether $B U D 5$ is also required to generate the bipolar pattern, several a/a diploid strains deleted for $B U D 5$ were constructed and analyzed. Wild-type a/ $\alpha$ cells generally showed bud scars clustered at both ends of the cell (Figure $6 \mathrm{~B}$ ). In contrast, a/ $\alpha$ Bud5 $5^{-}$cells exhibited a random pattern of bud scars. Thus the $B U D 5$ product, like the $B U D 1$ and $B U D 2$ products, is required for the bipolar pattern and must be produced in a/ $\alpha$ cells. Analysis of expression using Northern blots and a BUD5-lacZ fusion has confirmed that BUD5 is expressed in all cell types ( $J$. Chant, unpublished data).

\section{Effect of BUD5 When Carried on a High Copy Number Plasmid}

A $2.7 \mathrm{~kb}$ segment carrying BUD 5 but not MAT was inserted into the high copy number vector YEp24 to form plasmid pS7. This plasmid and control plasmid YEp24 were introduced into $\alpha B U D 5^{+}$strains, and the budding patterns were analyzed using the two assays. As shown in Figure 5C, the control $\alpha$ cells exhibited the expected axial behavior: $87 \%$ of microcolonies were class 4 . In contrast, the a strain carrying BUD5 on plasmid pS7 (Figure 5D) exhibited only $35 \%$ class 4 microcolonies. Perhaps more strikingly, $27 \%$ 


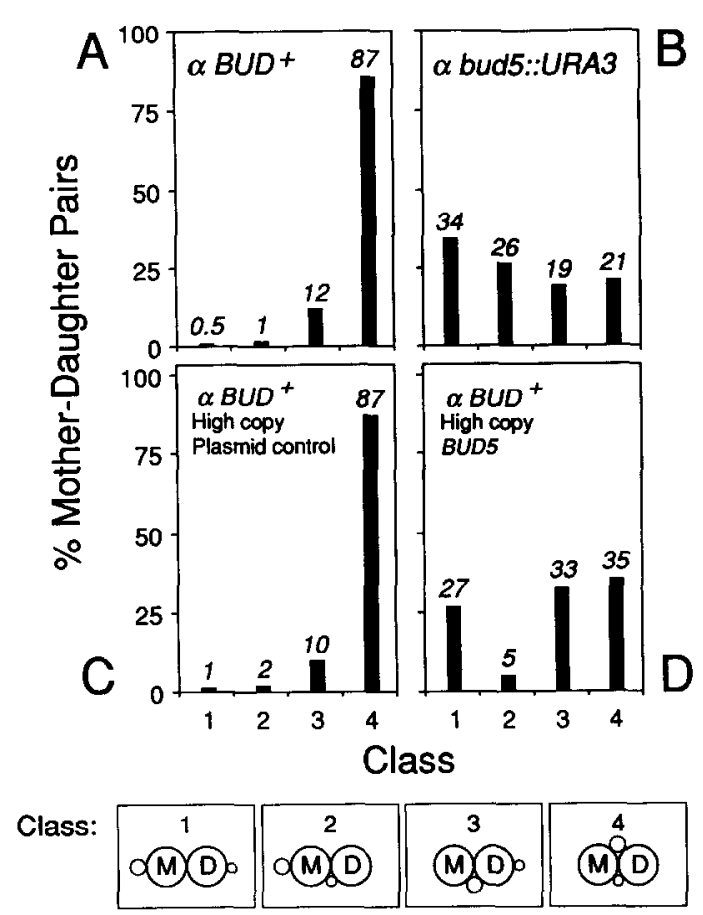

Figure 5. Budding Pattern Phenotypes of Strains That Lack or Overproduce BUD5

Log phase cells were spread on agar slabs, and their patterns of budding were examined microscopically at the two-cell/two-bud stage. Cells were scored to determine whether their buds emerged in the hemisphere proximal or distal to each cell's partner from the previous division. When mother cells (M) and daughter cells (D) are distinguished, four different patterns can be observed as indicated. Classes 1 and 3 are characteristic of the bipolar pattern; class 4 is characteristic of the axial pattern (Chant and Herskowitz, 1991). Approximately 400 microcolonies were scored for each strain. (A) a Bud ${ }^{+}(1237-13 C)$. The data in this panel are redrawn from Figure 2 of Chant and Herskowitz (1991). (B) a bud5::URA3 (205). These data were obtained at the same time as those shown in Figure 2 of Chant and Herskowitz (1991). (C) $\alpha$ Q BUD5 $5^{+}$strain $1237-13 C$ carrying vector YEp24. (D) a BUD5 strain 1237-13c carrying BUD5 ${ }^{+}$plasmid pS7.

of the microcolonies of this strain exhibited bipolar behavior (class 1), in contrast to just $1 \%$ of the control cells. Examination of bud scars confirmed that the axial pattern was disrupted: plasmid pS7 (but not YEp24) disrupted the haploid pattern of bud site selection, although at a lower frequency of cells than caused by deletion of BUD5 (data not shown). The presence of the plasmid had no effect on growth rate, on cell shape, or on any aspect of cell polarization other than budding pattern. We presume that pS7 causes overexpression of BUD5, although we have not confirmed this directly. The heterogeneous behavior of cells that carry pS7 might simply reflect differences in the level of BUD5 protein in these cells or it might indicate that these cells can choose the axial or random pattern in a stochastic manner.

\section{Interaction between BUD5 and BEM1, a Gene} Involved in Bud Emergence

A genetic interaction has been identified between bud5 and a new gene required for bud formation, called BEM1 (for "bud emergence"). Mutants R498 and A1467, both of which proved to carry BEM1 mutations, were among a large collection of ts lethal mutants obtained after heavy mutagenesis (Adams et al., 1990). These mutants arrested predominantly as large, unbudded cells at $37^{\circ} \mathrm{C}$. Segregation analysis of R498 indicated that mutations in two different genes were responsible for its temperature-sensitive growth defect at $37^{\circ} \mathrm{C}$. Tetrads from a cross of R498

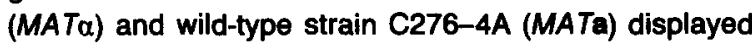
$\mathrm{Ts}^{+}: \mathrm{Ts}^{-}$segregation at $37^{\circ} \mathrm{C}$ of $4: 0,3: 1$, and $2: 2$ in a ratio of approximately 1:4:1. All Ts' segregants were MATa. In addition, all of the MAT $\alpha$ segregants (both $\mathrm{Ts}^{+}$and $\mathrm{Ts}^{-}$) and R498 itself had grossly abnormal patterns of bud site selection as determined by Calcofluor staining (see Figure 6). Thus, one of the mutations in R498 is tightly linked to MATa and is associated with randomization of bud position; this mutation seemed likely to be in BUD5. The other mutation is unlinked to MAT and caused a strong temperature-sensitive growth defect in combination with the bud5 mutation. When separated from the bud5 mutation, this mutation was weakly temperature sensitive: approximately half of the presumed $B U D 5^{+}$segregants (the MATa segregants) from the above cross were temperature sensitive at $39^{\circ} \mathrm{C}$, although not at $37^{\circ} \mathrm{C}$. As described below, this mutation was established to affect the BEM1 gene and was accordingly named bem1-2.

Three lines of evidence indicated that the mutation in strain R498 that is linked to MAT was in BUD5. First, this mutation (denoted bud5-498) failed to complement the bud5 deletion in strain Da2 (see Experimental Procedures). Second, the bud5-498 mutation and the bud5 deletion mutation bud5-de/X7-12 segregated as alleles: the diploid formed by mating R498-1A and Da2 revealed in four tetrads that all segregants had random bud scar patterns; temperature sensitivity at $37^{\circ} \mathrm{C}$ segregated $2: 2$. These segregation data indicate that both bud5-498 and bud5-delX7-12 accentuate the temperature-sensitive defect due to the bem1-2 mutation. Finally, the BUD5 $5^{+}$plasmid pK1 complemented the budding pattern defect of strain R498-1K (MATa bem 1-2 bud5) and allowed growth at $37^{\circ} \mathrm{C}$.

Strain A1467 proved to carry both an independent mutation in the BEM1 gene (bem 1-1) and a second temperature-sensitive mutation (see Experimental Procedures). The bem 1-1 mutation caused cells to arrest at $39^{\circ} \mathrm{C}$ as heterogeneous mixtures that included cells with large buds, cells with abnormally shaped buds, and approximately $60 \%$ unbudded cells (some of which were quite large). These strains did not exhibit alterations in bud site selection, as examined by staining with Calcofluor.

Complementation and segregation analyses confirmed that the bem 1-1 and bem 1-2 mutations are allelic and indicated that the bud5-498 mutation accentuates the temperature sensitivity of both of these bem1 mutations. A diploid obtained by crossing strains R498-1K (MATa bud5-498 bem1-2) and KYS6 (MATa bem 1-1) was temperature sensitive for growth at both $37^{\circ} \mathrm{C}$ and $39^{\circ} \mathrm{C}$. Upon sporulation, a temperature-sensitive growth defect at $37^{\circ} \mathrm{C}$ segregated two $\mathrm{Ts}^{+}$, two $\mathrm{Ts}^{-}$in ten of ten tetrads; all segregants were temperature sensitive for growth at $39^{\circ} \mathrm{C}$. All segregants 
A

$\alpha \mathrm{Bud}^{+}$

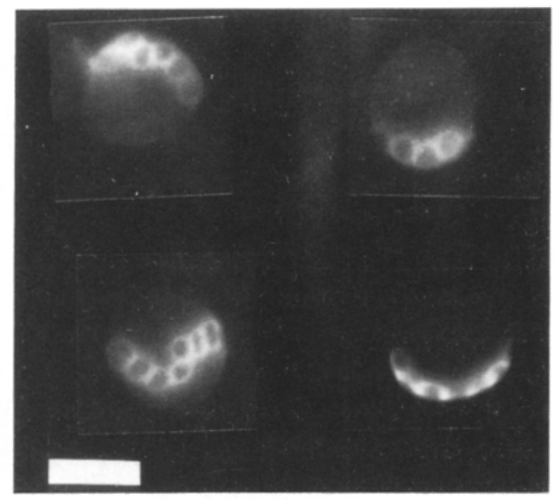

B

$\alpha$ Bud5 $^{-}$

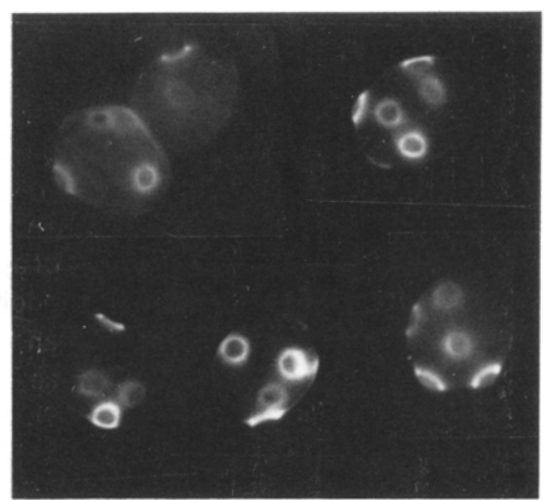

a/ $\alpha$ Bud5 $^{-}$

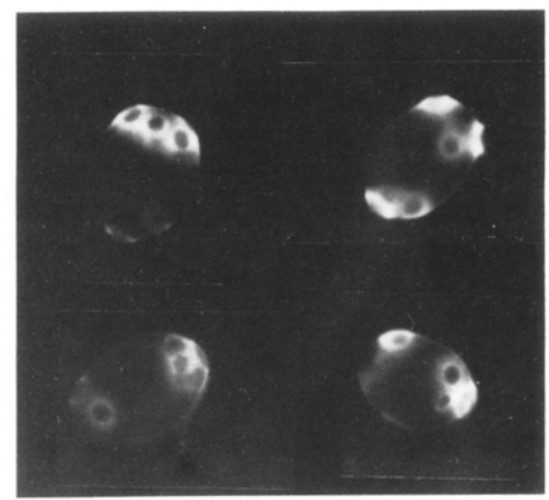

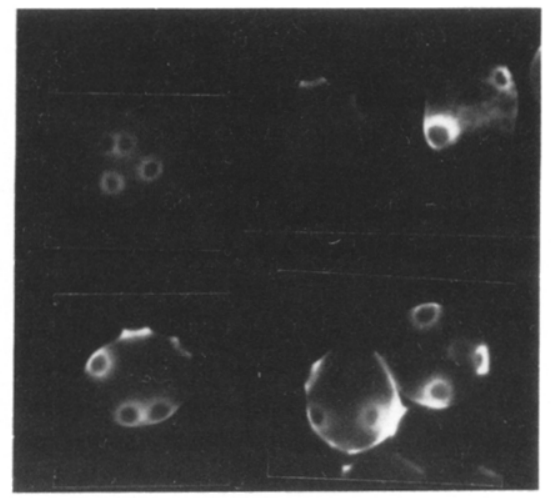

Figure 6. Bud Scar Phenotype of bud5- Mutants

(A) The patterns of bud scars exhibited by $\alpha$ Bud5 (left) and $\alpha$ Bud5 (right) strains (260 and 261, respectively)

(B) The patterns of bud scars exhibited by $a / \alpha$ Bud5 $5^{+}$(left) and $a / \alpha$ Bud5 $5^{-}$(right) strains (52 and 162 , respectively).

that were temperature sensitive at $37^{\circ} \mathrm{C}$ were MATa (indicating that they carried the bud5 mutation). BEM1 maps to the right arm of chromosome II, near tyr1 (Table 1). Complementation and segregation analyses established that this locus is identical to the BEM1 locus as identified

\begin{tabular}{|c|c|c|c|c|}
\hline \multirow[b]{2}{*}{ Cross } & \multirow[b]{2}{*}{ Marker Pair } & \multicolumn{3}{|c|}{ No. of Tetrads } \\
\hline & & $\begin{array}{l}\text { Parental } \\
\text { Ditype }\end{array}$ & $\begin{array}{l}\text { Tetra- } \\
\text { type }\end{array}$ & $\begin{array}{l}\text { Nonpa- } \\
\text { rental } \\
\text { Ditype }\end{array}$ \\
\hline KYS6 $\times \mathrm{MH7}$ & bem1-tyr1 & 18 & 4 & 0 \\
\hline $\mathrm{KYS} 2 \times \mathrm{MH} 7$ & ts $x-h i s 7$ & 27 & 4 & 0 \\
\hline \multirow[t]{3}{*}{ KYS32 $\times$ Y557" } & DEM1-1-BEM1 URA3 & 52 & 0 & 0 \\
\hline & bem-1-tyrt & 43 & 9 & 0 \\
\hline & BEM1-URA3-tyr1 & 43 & 9 & 0 \\
\hline
\end{tabular}

- Strain Y557 carries a URA3 plasmid that has integrated by homology at the BEM1 locus, as defined by the bem1-3 mutation (Bender and Pringle, 1991). The tsx mutation is described in Experimental Procedures. and mapped $6 \mathrm{cM}$ centromere distal to tyr 1 in independent studies (Bender and Pringle, 1991) (see Experimental Procedures).

\section{Terminal Phenotype of the bud5 bem1-2 \\ Double Mutant}

Examination of the terminal phenotype of the bud 5 bem 1-2 double mutant (diploid strain R498-HOK) demonstrated that this strain is defective in bud emergence-exhibiting delocalized cell surface growth-but progresses through the nuclear cycle. When a culture growing exponentially at $22^{\circ} \mathrm{C}$ was shifted to $37.5^{\circ} \mathrm{C}$, the population arrested with $>90 \%$ unbudded cells after increasing approximately 2-fold in cell number (Figure 7A). Growth continued after the failure of bud emergence: the arrested cells increased in both volume (Figures $8 \mathrm{~A}$ and $8 \mathrm{~B}$ ) and dry weight per cell (3-fold greater after $6 \mathrm{hr}$ at $37.5^{\circ} \mathrm{C}$ ).

As observed for other mutants defective in bud emergence (Hartwell et al., 1974; Adams et al., 1990), the nuclear cycle continued in the arrested cells. After $6 \mathrm{hr}$ at 

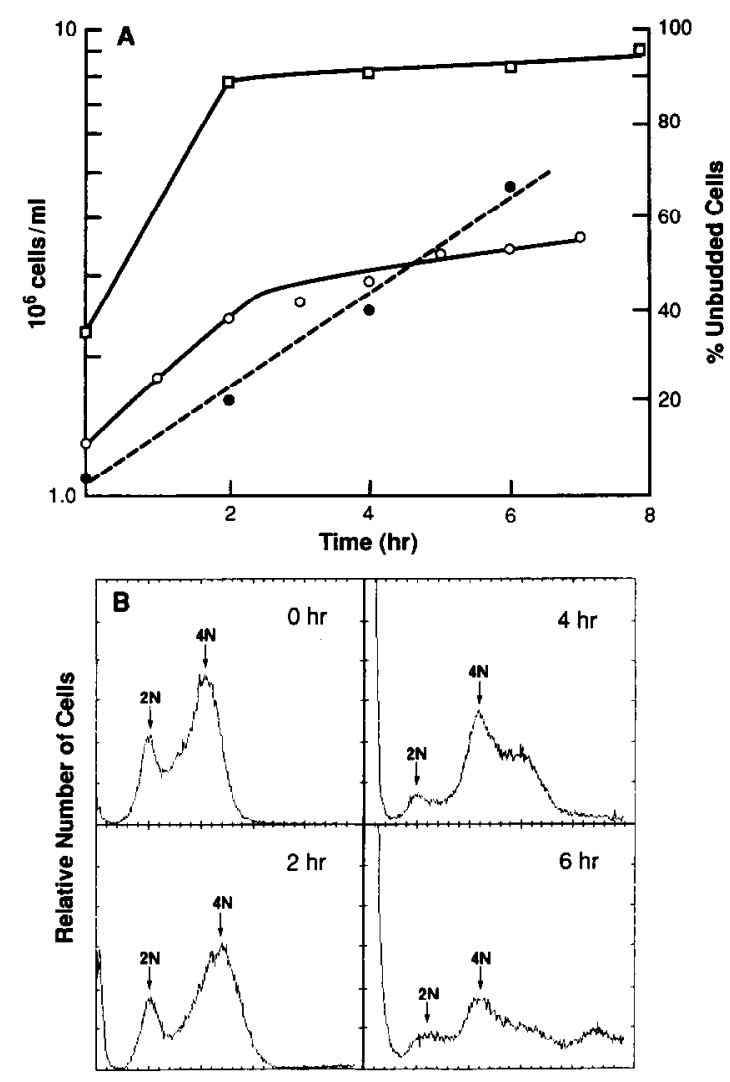

Relative DNA Content per Cell

Figure 7. Cell Cycle Arrest of the bud5 bem1-2 Double Mutant

(A) A culture of a/ $\alpha$ diploid strain R498-HOK growing exponentially at $22^{\circ} \mathrm{C}$ was shifted to $37.5^{\circ} \mathrm{C}$ at time $=0$. Cell numbers were determined for the $22^{\circ} \mathrm{C}$ (closed circles) and $37.5^{\circ} \mathrm{C}$ (open circles) cultures using the Coulter counter, and the percentages of unbudded cells (squares) at $37.5^{\circ} \mathrm{C}$ were determined by phase-contrast microscopy.

(B) Samples from the same cultures as shown in (A) were subjected to FACS analysis of DNA contents. The numbers in each panel indicate the times in hours after the shift to $37.5^{\circ} \mathrm{C}$; the positions of the $2 \mathrm{~N}$ (G1) and $4 \mathrm{~N}$ (G2 or mitotic) peaks are indicated.

$37.5^{\circ} \mathrm{C}, 10 \%$ of the cells had three or more nuclei, $47 \%$ had two nuclei, and $43 \%$ had a single nucleus (Figure $8 \mathrm{C}$ ). FACS analysis of cells shifted to high temperature showed a progressive decrease in the percentage of cells with a G1 DNA content and a corresponding increase in the percentage of cells with G2 or larger DNA contents (Figure 7B). Similarly, antitubulin immunofluorescence showed that by $6 \mathrm{hr}$ at $37.5^{\circ} \mathrm{C}$, approximately $86 \%$ of the uninucleate cells and approximately $70 \%$ of the cells with two nuclei had formed mitotic spindles (Figure 8D). These data provide further strong support for the hypothesis (Hartwell et al., 1974; Pringle and Hartwell, 1981; Adams et al., 1990) that the nuclear cycle is independent of bud emergence in the $\mathrm{S}$. cerevisiae cell cycle.

The round, enlarged shape of the arrested bud5 bem1 mutant cells suggested that their failure to bud reflected a general inability to polarize secretion and cell wall deposition, like the archetypal bud formation mutants defective in CDC24 (Sloat and Pringle, 1978; Sloat et al., 1981). This
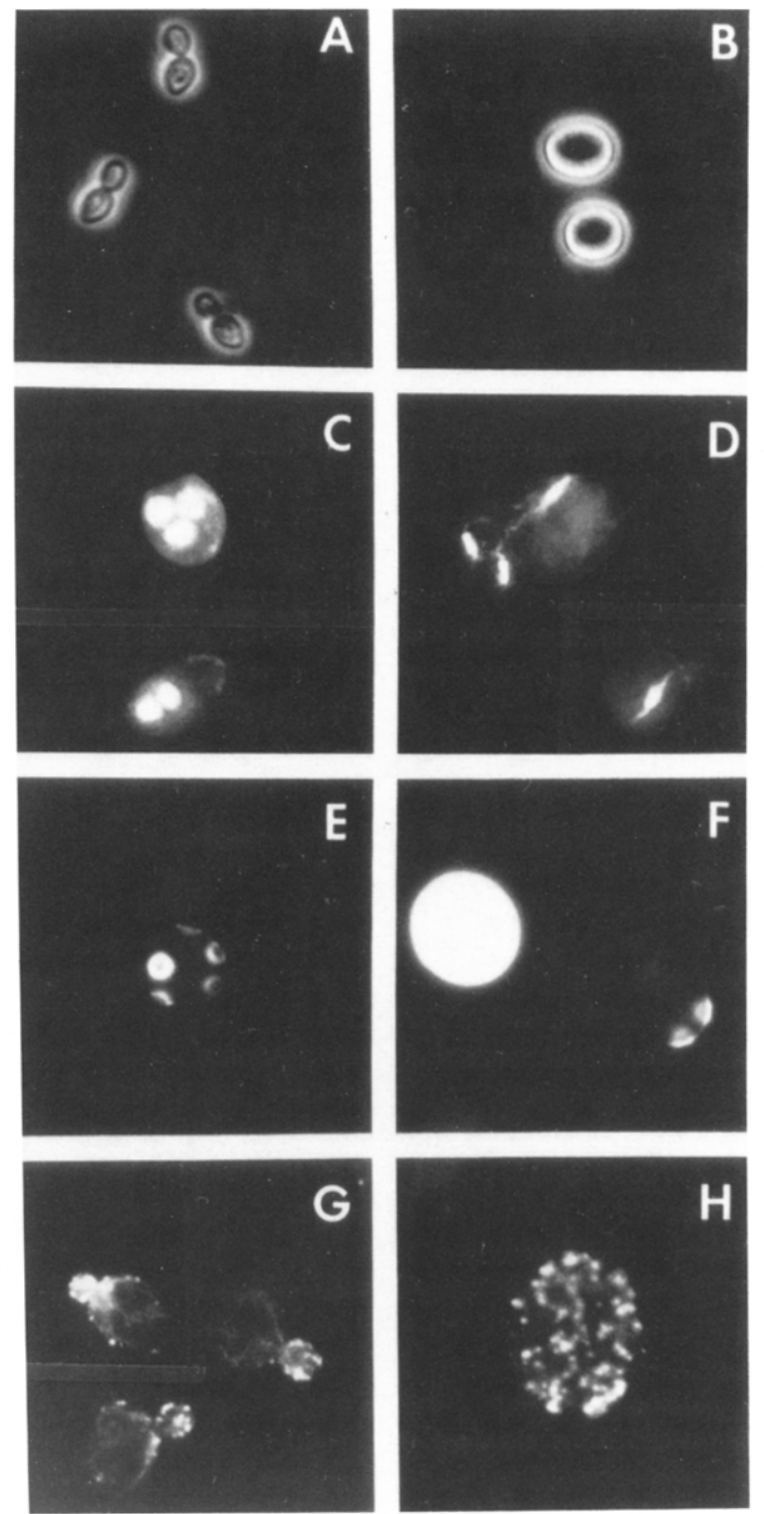

bem 1-2 Double Mutant

Cells from the cultures described in Figure 7 were examined. (A and B) Phase-contrast micrographs of cells fixed during growth at $22^{\circ} \mathrm{C}$ (A) or $6 \mathrm{hr}$ after the shift to $37.5^{\circ} \mathrm{C}(\mathrm{B})$. (C and D) Fluorescence micrographs of cells fixed and stained with DAPI (C) or with tubulin-specific antibodies (D) $6 \mathrm{hr}$ after the shift to $37.5^{\circ} \mathrm{C}$. (E and F) Fluorescence micrographs of celis flxed and stained with Calcofluor during growth at $22^{\circ} \mathrm{C}$ (right-hand cell in $[E]$ and $[F]$; note the randomized budding pattern of the cell in [E]) or $6 \mathrm{hr}$ after the shift to $37.5^{\circ} \mathrm{C}$ (left-hand cell in [F]). ( $G$ and $H$ ) Fluorescence micrographs of cells fixed and stained with actin-specific antibodies during growth at $22^{\circ} \mathrm{C}(\mathrm{G})$ or $6 \mathrm{hr}$ after the shift to $37.5^{\circ} \mathrm{C}(\mathrm{H})$.

hypothesis was supported by analysis of chitin deposition. In contrast to the presence of distinct bud scars on the mutant cells grown at $22^{\circ} \mathrm{C}$ (Figures $8 \mathrm{E}$ and $8 \mathrm{~F}$ ), uniformly bright staining was observed for the cells grown at $37.5^{\circ} \mathrm{C}$ (Figure 8F), indicating a nonlocalized deposition of cell wall chitin (Pringle et al., 1989). Consistent with the hypoth- 
esis that the actin cytoskeleton is involved in determining the pattern of cell surface deposition (Adams and Pringle, 1984; Kilmartin and Adams, 1984; Novick and Botstein, 1985; Drubin et al., 1988; Haarer et al., 1990), we observed that the actin of arrested R498-HOK cells appeared uniformly distributed (Figure $8 \mathrm{H}$ ), in contrast to the normal asymmetric distribution found in cells grown at $22^{\circ} \mathrm{C}$ (Figure $8 \mathrm{G})$.

\section{Discussion}

We have identified two new genes, $B U D 5$ and $B E M 1$, that play distinct but functionally interacting roles in generating cellular spatial organization. $B U D 5$ is a member of the set of genes (which includes BUD1, BUD2, BUD3, and BUD4) that is required for choosing the position on the cell surface where the new bud will form (Chant and Herskowitz, 1991; Bender and Pringle, 1989). We have not found any functional significance to the location of BUD5 adjacent to the mating-type locus: BUD5 is expressed in all cell types, and the products of MAT are not necessary for the axial budding pattern. BUD5 resembles $B U D 1$ and $B U D 2$ in being required for both axial and bipolar patterns. BEM1 is a member of the set of genes (which includes CDC24, $C D C 42$, and $C D C 43$ ) that is required for the organization of cell surface growth. These two sets of genes appear distinct from each other in that the BUD genes are nonessential and are not needed for establishing cell polarity. (This property of $B U D$ genes has been tested for BUD1, $B U D 3$, and $B U D 5$ and is presumed to be true for $B U D 2$ and $B U D 4$; see Chant and Herskowitz, 1991.) In contrast, the CDC24 group of genes is essential and is needed for establishing cell polarity. Several observations (Bender and Pringle, 1989; Chant and Herskowitz, 1991; see below) have led to the hypothesis that the products involved in bud site selection guide the positioning of the products necessary for cell polarization and bud emergence. We have discovered a functional interaction between BUD5 and $B E M 1$ that gives further support to this view. Finally, we have determined the nucleotide sequence of BUD5 and found that it encodes a polypeptide with similarity to $S$. cerevisiae CDC25, an activator of yeast RAS1 and RAS2 (Broek et al., 1987). Two proteins involved in generating cellular spatial organization (BUD1 and CDC42) have similarity to RAS (Bender and Pringle, 1989; Johnson and Pringle, 1990) and might be targets of BUD5. Interaction between BUD5 and one or both of these proteins might play a role in monitoring assembly of a structure involved in bud formation.

\section{Functional Interaction between Bud Site Selection Gene BUD5 and Bud Formation Gene BEM1}

The BEM1 gene has been recently identified in three independent ways. Here we describe its discovery in two temperature-sensitive mutants. It has also been identified because it exhibits synthetic lethality with an msb1 deletion (Bender and Pringle, 1991); MSB1 was itself identified (Bender and Pringle, 1989) as a multicopy suppressor of a cdc24-ts mutation. When separated from the msb1 muta-

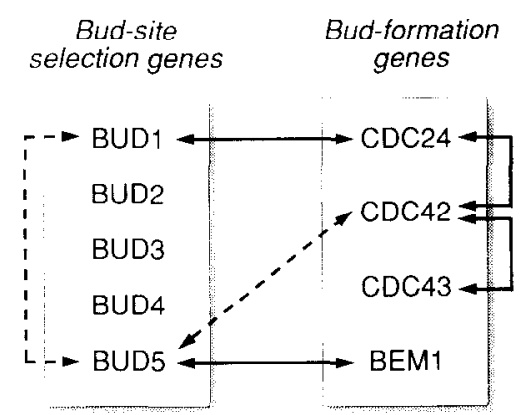

Figure 9. Interactions between Genes Necessary for Bud Site Selection and Bud Formation

The two groups of genes are distinguished from each other primarily on the basis that the bud site selection genes are nonessential and are not necessary for the polarization of cell surface growth; they are required only for choosing the site at which such polarization will occur. The bud formation genes are essential and are required for the polarization of cell surface growth, and hence for bud formation. A variety of observations indicate that members of these groups of genes and proteins interact with each other (see text). Solid lines indicate known genetic interactions - suppression of ts mutations by high copy number plasmids (BUD1-CDC24 and CDC24-CDC42) or double-mutant synergism (BUD5-BEM1 and CDC42-CDC43). Dashed lines (BUD5$B U D 1$ and $B U D 5-C D C 42$ ) indicate possible interactions deduced from nucleotide sequences. We note that perturbation of bud formation genes (certain alleles of CDC24 [Sloat et al., 1981] and overproduction of CDC42 [Johnson and Pringle, 1990]) can cause alterations in bud site selection.

tion, these bem 1 mutations caused temperature-sensitive growth and accumulation of large, unbudded, multinucleate cells even at permissive temperature. Finally, BEM1 has been identified in mutants that exhibit an altered morphological response to mating factors (J. Chenevert et al., unpublished data).

Ordinarily, mutations in BUD5 (even complete deletions of the gene) have no effect on cell growth. However, we have observed that the combination of a bud5 mutation with an otherwise only mildly deleterious mutation in BEM1 resulted in a tight temperature-sensitive growth defect at $37^{\circ} \mathrm{C}$. At this temperature, the bud 5 bem 1 double mutant exhibited all of the phenotypes characteristic of a mutant defective in one of the CDC24 group of genes, arresting as large, unbudded, multinucleate cells in which cell wall growth and the actin cytoskeleton were uniformly distributed instead of being polarized. The behavior of these double mutants and of the bem1 BUD5 $5^{+}$strains (Bender and Pringle, 1991) suggest that the BEM1 product is necessary for bud emergence, that is, for organization of growth of the bud. The distinctive behavior of double mutants defective in both BUD5 and BEM1 provides another indication that the BUD gene products interact in some way with proteins such as CDC24 and BEM1 that are necessary for polarizing the yeast cell and restricting growth to a specific site. Although there are a variety of possible explanations for the behavior of the double mutant, an appealing hypothesis is that BUD5 physically interacts with BEM1 and that this interaction can stabilize an enfeebled form of BEM1.

Several other functional interactions have been demon- 
strated among the genes involved in bud site selection and cell polarization (Figure 9). In particular, overproduction of either BUD1/RSR1 or CDC42 can partially suppress the temperature-sensitive growth defects of certain coc24 mutants (Bender and Pringle, 1989), and temperature-sensitive cdc42 and cdc43 mutations display synthetic lethality at $23^{\circ} \mathrm{C}$ (Adams et al., 1990). Below we present the argument that BUD5 may interact with BUD1 or CDC42. These observations support the hypothesis that the proteins involved in bud site selection form a complex at the chosen site for budding and physically recruit the proteins responsible for restricting bud growth to that site. The latter proteins (which include CDC24, CDC42, and BEM1) would presumably direct the assembly of the actin cytoskeleton, which appears to be immediately responsible for the polarized movement of secretory vesicles to the budding site (Kilmartin and Adams, 1984; Adams and Pringle, 1984; Novick and Botstein, 1985; Drubin et al., 1988; Haarer et al., 1990). It is interesting to note that alleles of CDC24 exist that allow normal bud formation but cause a random budding pattern (Sloat et al., 1981). These mutants might be specifically defective in interacting with the BUD proteins.

High copy number plasmids that carry BUD5 cause some disruption in the axial budding pattern of an $\alpha$ strain. Overproduction of CDC42 product is also known to cause disruption of the budding pattern (Johnson and Pringle, 1990). The sensitivity of the bud site selection process to the levels of BUD5 and CDC42 suggests that certain of the BUD proteins and certain of the CDC24 group of proteins may form a complex that has a critical stoichiometry. Similar types of inhibition caused by protein imbalances are discussed by Meeks-Wagner and Hartwell (1986).

\section{BUD5 May Act as a GDP-GTP Exchange Factor for a RAS-like Target}

BUD5 and the carboxy-terminal 430 amino acids of the S. cerevisiae CDC25 product display $20 \%$ identity, with the identities distributed throughout the polypeptide chains (Figure 4A). Based on genetic and physiological experiments, CDC25 has been proposed to activate yeast RAS1 and RAS2 by catalyzing GDP-GTP exchange (Camonis et al., 1986; Daniel et al., 1987; Broek et al., 1987). Guanine nucleotide exchange activity has recently been demonstrated for CDC25 (Jones et al., 1991) and has also been shown for a related protein, SCD25 (Boy-Marcotte et al., 1989; Créchet et al., 1990).

Two observations indicate that the structural similarity between BUD5 and CDC25 is functionally significant. First, the segment of CDC25 that contains similarity to BUD5 is sufficient to regulate RAS; that is, it complements a cdc25 mutation in vivo (Boy-Marcotte et al., 1989). Second, recent observations suggest that BUD5 may be capable of physically interacting with yeast RAS. Earlier studies (Powers et al., 1989) showed that a high copy number plasmid carrying $C D C 25$ can alleviate the growth defect due to certain mutations in RAS2. Suppression is thought to result from physical interaction between CDC25 and RAS2. In screening a library for other plasmids with this ability, Powers et al. (1991) observed that high copy num- ber plasmids carrying BUD5 exhibited partial suppression. Although it is unlikely that BUD5 plays a role in activating RAS1 and RAS2 in wild-type cells, these results are consistent with the view that it can interact with RAS2 in a CDC25-like manner when overproduced.

Based on the sequence similarities and functional information just described, we predict that BUD5 catalyzes GDP-GTP exchange for one or more RAS-like proteins. Two obvious candidates are known: the predicted BUD1/ $R S R 1$ product has $57 \%$ identity to human $\mathrm{H}$-ras and $58 \%$ identity to $S$. cerevisiae RAS 1 over a segment of 120 amino acids (Bender and Pringle, 1989), and the CDC42 protein is $30 \%-40 \%$ identical to various RAS proteins over its entire length and even more closely related (52\%-80\% identical) to members of the Rho subfamily of RAS-related proteins (Johnson and Pringle, 1990).

A variety of roles for RAS and other guanine nucleotidebinding proteins have been established or suggested (Bourne et al., 1990; Hall, 1990). We can imagine at least two models for the roles of BUD1 and BUD5 in bud site selection. In the first model (see Bourne et al., 1990), BUD1 protein (in its GTP-bound form) acts to bring other proteins (for example, CDC24 or other products) to the budding site. Having reached this destination, the GTP is hydrolyzed to GDP. BUD1-GDP then leaves the budding site and can be acted upon once again by BUD5 to regenerate BUD1-GTP. In the second model, juxtaposition of BUD1 and BUD5 is used to monitor macromolecular assembly. According to this scheme, BUD1 (in its GDP-bound state) and BUD5 become independently associated with the chosen site (which might be determined by the BUD3 and BUD4 products, at least in a and $\alpha$ cells). Only when they are bound to their proper sites are they appropriately positioned to interact with each other. At this time, BUD5 catalyzes GDP-GTP exchange for BUD1, which causes a conformational change that allows the next step in the assembly process to take place.

\section{A Growing Family of CDC25-like Proteins}

In addition to BUD5 and SCD25, at least two other proteins related to CDC25 are known, LTE1 of S. cerevisiae (Wickner et al., 1987) and ste6 of Schizosaccharomyces pombe (Hughes et al., 1990). The function of LTE1 is unknown; deletion mutants are cold sensitive for growth. The ste 6 product is required for mating and has a potential RASrelated target, ste5 (also known as ras1), which is also required for mating (Hughes et al., 1990). A comparison of two segments of BUD5 with CDC25, SCD25, ste6, and LTE1 is shown in Figure 4B; the conserved residues may identify positions of contact with the companion GTP. binding proteins. This growing family of proteins related to CDC25 suggests that the activities of many RAS-related proteins may be regulated by proteins of the CDC25 type (Powers et al., 1989; Hall, 1990; Levitzki, 1990). The availability of the sequences for several members of this family should now facilitate the identification of additional proteins of this type.

The studies described here identify a presumptive additional component in the two-state regulatory module whose centerpiece is a nucleotide-bound ras protein. They 
Table 2. Yeast Strains and Plasmids Used in I his Study

\begin{tabular}{|c|c|c|}
\hline \multicolumn{3}{|c|}{ Yeast Strains } \\
\hline Name & Relevant Markers & Source/Comments \\
\hline $7-1$ & MATa1 HMLa HMRa his4 trp1 ura3 & Chant and Herskowitz (1991) \\
\hline 49 & 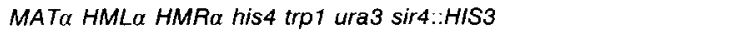 & Chant and Herskowitz (1991) \\
\hline 52 & MATa/MATa his4/his4 trp1/trp1 ura3/ura3 & Chant and Herskowitz (1991) \\
\hline 145 & MATa bud5::URA3 his 4 trp1 ura3 & This study \\
\hline 162 & MATa/MATa bud5::URA3/bud5::URA3 his $4 /$ his 4 trp1/trp 1 ura3/ura3 & Ihis study \\
\hline 205 & MATQ bud5::URA3 his 4 trp1 ura3 & This study \\
\hline 219 & MATa HML $\alpha$ HMR $\alpha$ his4 trp1 ura3 + YEp24 & $1237-13 C+Y E p 24$ \\
\hline 220 & MAT $\alpha$ HML $\alpha$ HMR $\alpha$ his 4 trp1 ura3 + pS7 & $1237-13 C+p S 7$ \\
\hline $260^{\circ}$ & 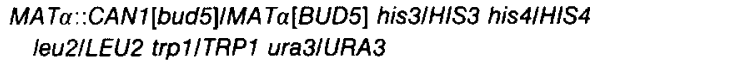 & \\
\hline $261^{a}$ & 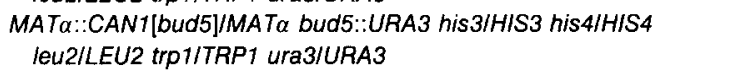 & \\
\hline $1186^{\mathrm{a}}$ & MATa::CAN1[bud5] his leu2 trp1 ura3 rme1 & M. Hall \\
\hline $1237-13 \mathrm{C}$ & 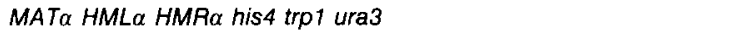 & A. Mitchell \\
\hline $1237-1$ & MATa HML $\alpha$ HMR $\alpha$ his 4 trp 1 ura3 & Chant and Herskowitz (1991) \\
\hline 1783 & MATa his 4 leu2 $\operatorname{trp} 1$ ura $3 \mathrm{can}^{\mathrm{R}}$ & Tatchell et al. (1981) \\
\hline 1784 & MATa his4 leu2 trp1 ura $3 \mathrm{can}^{\mathrm{A}}$ & Tatchell et al. (1981) \\
\hline Da2 & MATa-X7-12 his 4 leu $2 \operatorname{trp} 1$ ura3 can $1^{\mathrm{R}}$ & K. Tatchell \\
\hline A1467 & MA / a bem1-1 ts $x$ & This study (see text) \\
\hline C276-4A & MATa (Ts' prototroph) & Wilkinson and Pringle (1974) \\
\hline C276-4B & MATa (Ts ${ }^{+}$prototroph) & Wilkinson and Pringle (1974) \\
\hline KYS2 & MATa ts $x$ & This study \\
\hline KYS6 & MAT $\alpha$ bem1-1 & This study \\
\hline KYS32 & MATa bem1-1 ura3 & This study ${ }^{c}$ \\
\hline R498 & MATa bem1-2 bud5 & This study (see text) \\
\hline R498-1A & MAT $\alpha$ bem1-2 bud5 & This study \\
\hline R498-1K & MATa bem $1-2$ bud 5 ura3 & This study ${ }^{\theta}$ \\
\hline R498-HOK & MATa/MATa bem1-2/bem1-2 bud5/bud5 URA3/ura3 & $R 498-1 A \times R 498-1 K$ \\
\hline Y557 & MATa BEM1 URA3 ura3 leu2 trp1 lys2 tyr1 & $\begin{array}{l}\text { A. Bender; similar to Y541 } \\
\text { (Bender and Pringle, 1991) }\end{array}$ \\
\hline MH7 & MATa lys2 tyr1 his7 gic6-1 & J. Pringle \\
\hline \multicolumn{3}{|l|}{ Plasmids } \\
\hline Name & Description & Source/Comments \\
\hline pJM3 & $4.2 \mathrm{~kb}$ HindlII-HindllI fragment containing MATa in YCp50 & J. Margolskee \\
\hline pJM9 & $4.2 \mathrm{~kb}$ HindlII-HindlII fragment containing $M A T \alpha$ in $Y C p 50$ & J. Margolskee \\
\hline pK1 & $15 \mathrm{~kb}$ Sau3A fragment containing BUD5 and MATa in $Y C p 50$ & W. Kruger; Rose (1987) \\
\hline pB1 & pK1 with BamHI linker insert downstream of BUD5 & This study \\
\hline ps7 & $2.7 \mathrm{~kb}$ Xbal-BamHI fragment of BUD5 in YEp24 & This study \\
\hline pK62 & $2.7 \mathrm{~kb}$ Xbal-BamHI fragment of BUD5 in pUC19 & This study \\
\hline pK62-1 & $\begin{array}{l}\text { BUD5 coding sequence replaced by segment containing URA3; } \\
\text { derivative of pK62 }\end{array}$ & See Experimental Procedures \\
\hline pMIN1 & $2.7 \mathrm{~kb}$ Xbal-BamHI fragment of BUD5 from pK62 in YCp50 & This study \\
\hline YEp24 & URA3, high copy number $(2 \mu)$ vector & \\
\hline
\end{tabular}

a MATa::CAN1 (MAT $\alpha-\times 130-141:$ CAN1) is a substitution of MATa by CAN1 (M. Hall), in which the BUD5 gene is deleted (see Figure 1).

' Segregants from the third backcross of A1467 to C276-4A and C276-4B.

" Segregant from a cross of SY1263 (Bender and Sprague, 1989) to a segregant from the third backcross of A1467 to C276-4A and C276-4B.

'Segregant from the third backcross of R498 to C276-4A and C276-4B.

- Constructed by using plasmid pGAL-HO (Herskowitz and Jensen, 1991) to switch the mating type of a MATu segregant from the cross of R498 to SY1229 (Bender and Sprague, 1989).

${ }^{1}$ Derived from a series of crosses between strain A364A (Hartwell, 1967), C276-4B, and a glc6-1 mutant (J. Pringle, unpublished data) derived from C276-4B.

provide further demonstration of the diverse roles that the ras protein switch can play-in this case, a role in cellular morphogenesis. It remains to be determined whether other components analogous to GAP (Trahey and McCormick, 1987) or to the yeast analogs, IRA1 and IRA2 (Tanaka et al., 1990), will also be found to govern RSR1/BUD1 and CDC42.

\section{Experimental Procedures}

\section{Strains}

Yeast strains and plasmids are described in Table 2. pK1 was obtained from a library of partially digested Sau3A fragments (Rose et al., 1987). The bud5::URA3 mutation was constructed by replacing the $1467 \mathrm{bp}$ HindIII-Xbal segment from plasmid pK62 with the Hindlil-Hindlll segment containing URA3 from pSM31 (obtained from S. Michaelis). Strains used in. Figure 1 are all derivatives of 1783 and 1784 and carry mutations $\times 182$ (1786), X189 (1787), X50 (1883), and X8 (2013) (Tatchell et al., 1981).

\section{Microbiological Methods}

Yeast genetic procedures and media are described by Sherman et al. (1982) and Chant and Herskowitz (1991); characterization of bem1 strains utilized medium YM-P (Lillie and Pringle, 1980). Transformation was carried out by the procedure of Ito et al. (1983). Inserts of transpo- 
son Tn 1000 into plasmid pK1, which contains BUD5, were isolated as described by Banuett and Herskowitz (1987). Procedures for fixing cells with formaldehyde, sonicating to disperse clumps, determining total cell numbers with the Coulter counter, examining cell morphologies and determining the proportions of unbudded cells by phasecontrast microscopy, and measuring dry weights by filtration have been described previously (Pringle and Mor, 1975; Pringle et al., 1989). For flow cytometry (FACS) analysis, DNA was stained with propidium iodide (Sigma P4170) after treatment of cells with RNAase (Sigma R4875) and pepsin (Sigma P6887) as described by Hutter and Eipel (1978); DNA contents were then determined using an EPICS cytometer (Coulter Electronics, Hialeah, FL). Immunofluorescence and staining of cells with DAPI and Calcofluor were performed as described by Pringle et al. (1989); immunofluorescence used antibodies against tubulin (Kilmartin ot al., 1982) or actin (Haarer ot al., 1990). Other assays of budding pattern were conducted as described by Chant and Herskowitz (1991).

\section{Repair of BUD5 by Mating-Type Switching}

The HO-containing plasmid $\mathrm{YCp50-HO}$ was introduced into Bud strains 2013 (MAT $\alpha-X 8$ ) and Da2 (MATa-X7-12), and a/a diploids were isolated from transformants. Derivatives that had lost the plasmid were isolated, the a/a strains sporulated, and segregants were analyzed for mating type and for budding pattern. In all 12 segregants analyzed for each of the two strains, switching of the MAT-deletion mutations (which were Bud') to MATa or MATa resulted in a simultaneous switch to the Bud $^{+}$phenotype (axial budding pattern).

\section{Nucleotide Sequence Determination}

Segments of BUD5 were subcloned in either M13mp18 or M13mp19 and sequenced using the dideoxy chain termination method of Sanger et al. (1977). The nucleotide sequence of the entire coding region of BUD5 (1.6 kb) was determined for both strands. Where BUD5 overlaps MAT, six differences (two substitutions and four additions) were found between our sequence and the published sequence (Astell et al., 1981). Some of these are particularly significant since they result in an extension of the BUD5 open reading frame an additional 104 amino acids at the amino terminus. $M$. Jacquet (personal communication) alerted us to the existence of discrepancies between the published sequence and their independently determined sequence.

\section{Construction and Analysis of Strains Deleted for BUD5}

Plasmid pK62-1 (Table 2 and see above) was linearized by cleavage with BamHI and Bgll and used to transform a/a diploid strain 52. Ura ${ }^{+}$ transformants were isolated and sporulated. In seven of seven diploids tested, $\mathrm{Ura}^{+}$, abnormal budding pattern, and mating type cosegregated and segregated 2:2 for all complete tetrads analyzed (five from each diploid). One tetrad from each diploid was analyzed by Southern blotting to confirm that gene replacement had occurred by homologous recombination (data not shown). The mating ability of the bud5 $\mathbf{s e g}$ regants with wild-type cells was assayed by mating patch tests, and pheromone production was assayed by halo assays (Sprague, 1991). The effect of the bud5 $5^{-}$mutation on growth rate was assessed by comparison of colony sizes of sister segregants on rich medium.

\section{Analyais of Temperature-Senaitive Mutant and Relationship} of bem1 Mutation to Independently lsolated Mutations in the BEM1 Gene

\section{R498}

The diploid formed by mating a MATa R498 derivative (R498-1A) to a bud5 deletion strain (Da2) displayed a fully randomized bud scar pattern, indicating that $R 498$ contains a mutation (denoted bud5-498) that does not complement the bud5 deletion. In contrast, the diploid formed by mating R498-1A to wild-type strain C276-4A displayed a bud scar pattern that was only mildly abnormal.

\section{A1467}

The original mutant strain A1467 was shown to carry two temperature sensitive mutations, one of which (bem1-1) caused temperaturesensitive growth at $39^{\circ} \mathrm{C}$ but not at $37^{\circ} \mathrm{C}$. The other mutation (which caused temperature-sensitive growth even at $37^{\circ} \mathrm{C}$ ) is denoted tsx. Cells carrying the tsx mutation exhibited a normal-looking mixture of budded and unbudded cells when arrested at nonpermissive tempera- ture and, either with or without the bem7-1 mutation, did not exhibit alterations in bud site selection as assayed by Calcofluor staining. The tsx mutation maps to the right arm of chromosome II, $8 \mathrm{cM}$ centromere proximal to h/s7 (Table 1 and data not shown).

Identlty of bem1-1 and Independently Identified Mutations

\section{in BEM1}

The bem1-1 aliele from strain A1467 and the bem1-3 allele in strains identified by Bender and Pringle (1991) do not complement: diploids formed by mating bem1-1 and bem 1-3 strains grow poorly, if at all, at $37^{\circ} \mathrm{C}$ or $39^{\circ} \mathrm{C}$ (A. Bender, personal communication). Moreover, introduction of the cloned BEM1 gene carried on a YEp24-based plasmid (Bender and Pringle, 1991) into the bem1-1 strain KYS32 yielded a strain that was $\mathrm{Ts}^{+}$at $39^{\circ} \mathrm{C}$. Finally, bem $1-1$ showed tight linkage to a URA3 insertion at the bem1-3 site (Table 1).

\section{Acknowledgments}

We thank Henry Bourne, Fred Chang, Tony Hyman, Sandy Johnson, Doug Johnson, and Alan Bender for discussion and for comments on the manuscript; Rich Longnecker and Doug Johnson for assistance in parts of this work; Warren Kruger for inadvertently cloning BUD5; Kelly Tatchell for strains and information; Dan Broek and Scott Powers for communicating information prior to publication; Michel Jacquet for alerting us to disparities in the published sequence of the mating-type locus; Linda Riles and Jim Dutchik for helping map BEM1 and tsX; members of the Simpson Flow Cytometry Laboratory for assistance with the FACS analysis; and Kerrie Andow for figures. This work was supported by research grants from the NIH and from the Weingart Foundation to I. H. and by a research grant from the NIH (GM 31006) to J. R. P. J. C. was supported by fellowships from the Medical Research Council of Canada, the Lucille P. Markey Charitable Trust, and the Weingart Foundation; K. C. was supported by NIH training grant GM 07544.

The costs of publication of this article were defrayed in part by the payment of page charges. This article must therefore be hereby marked "advertisement" in accordance with 18 USC Section 1734 solely to indicate this fact.

Received February 27, 1991; revised May 7, 1991

\section{Reterences}

Adams, A., and Pringle, J. (1984). Localization of actin and tubulin in wild type and morphogenic-mutant Saccharomyces cerevisiae. J. Cell Biol. 98, 934-945.

Adams, A. E. M., Johnson, D. I., Longnecker, R. M., Sloat, B. F., and Pringle, J.R. (1990). CDC42 and CDC43, two additional genes involved in budding and the establishment of cell polarity in the yeast Saccharomyces cerevisiae. J. Cell Biol. 111, 131-142.

Astell, C. R., Ahlstrom-Jonasson, L., Smith, M., Tatchell, K., Nasmyth, K. A., and Hall, B. D. (1981). The sequence of the DNAs coding for the mating-type loci of Saccharomyces cerevisiae. Cell 27, 15-23.

Banuett, F., and Herskowitz, I. (1987). Identification of polypeptides encoded by an Escherichia coli locus (hflA) that governs the lysislysogeny decision of bacteriophage lambda. J. Bacteriol. 169, 40764085.

Bender, A., and Pringle, J. R. (1989). Multicopy suppression of the cdc24 budding defect in yeast by CDC42 and three newly identified genes including the ras-related gene RSR1. Proc. Natl. Acad. Sci. USA 86, 9976-9980.

Bender, A., and Pringle, J. R. (1991). Use of a screen for synthetic lethal and multicopy suppressee mutants to identify two new genes involved in morphogenesis in Saccharomyces cerevisiae. Mol. Cell. Biol. 11, 1295-1305.

Bender, A., and Sprague, G. F., Jr. (1989). Pheromones and pheromone receptors are the primary determinants of mating specificity in the yeast Saccharomyces cerevisiae. Genetics 121, 463-476.

Bourne, H. R., Sanders, D. A., and McCormick, F. (1990). The GTPase superfamily: a conserved switch for diverse cell functions. Nature 348 , 125-132.

Boy-Marcotte, E., Damak, F., Camonis, J., Garreau, H., and Jacquet, 
M. (1989). The C-terminal part of a gene partially homologous to CDC25 gene suppresses the coc25-5 mutation in Saccharomyces cerevisiae. Gene 77, 21-30.

Broek, D., Toda, T., Michaeli, T., Levin, L., Birchmeier, C., Zoller, M., Powers, S., and Wigler, M. (1987). The S. cerevisiae CDC25 gene product regulates the RAS/adenylate cyclase pathway. Cell 48,789 799.

Camonis, J. H., Kalekine, M., Bernard, G., Garreau, H., Boy-Marcotte, $E$., and Jacquet, M. (1986). Characterization, cloning and sequence analysis of the CDC25 gene which controls the cyclic AMP level of Saccharomyces cerevisiae. EMBO J. 5, 375-380.

Chant, J., and Herskowitz, I. (1991). Genetic control of bud site selection in yeast by a set of gene products that constitute a morphogenetic pathway. Cell, this issue.

Créchet, J.-B., Poullet, P., Mistou, M.-Y., Parmeggiani, A., Camonis, J., Boy-Marcotte, E., Damak, F., and Jacquet, M. (1990). Enhancement of the GDP-GTP exchange of RAS proteins by the carboxyl-terminal domain of SCD25. Science 248, 866-868.

Daniel, J., Becker, J. M., Enari, E., and Levitzki, A. (1987). The activation of adenylate cyclase by guanyl nucleotide in Saccharomyces cerevisiae is controlled by the CDC25 START gene product. Mol. Cell. Biol. 7, 3857-3861

Drubin, D. G., Miller, K. G., and Botstein, D. (1988). Yeast actin-binding proteins: evidence for a role in morphogenesis. J. Cell Biol. 107, 25512561

Finegold, A. A., Johnson, D. I., Farnsworth, C. C., Gelb, M. H., Judd, M. R., Glomset, J. A., and Tamanoi, F. (1991). Geranylgeranyl:protein transterase of Saccharomyces cerevisiae is specific for Cys-Xaa-XaaLeu motif proteins and requires the CDC43 gene product, but not the DPR1 gene product. Proc. Natl. Acad. Sci. USA, in press.

Haarer, B. K., Lillie, S. H., Adams, A. E. M., Magdolen, V., Bandlow, W., and Brown, S. S. (1990). Purification of profilin from Saccharomyces cerevisiae and analysis of profilin-deficient cells. J. Cell Biol. 110, 105114.

Hall, A. (1990). The cellular functions of small GTP-binding proteins. Science 249, 635-640.

Hartwell, L. H. (1967). Macromolecule synthesis in temperaturesensitive mutants of yeast. J. Bacteriol. 93, 1662-1670.

Hartwell, L. H., Culotti, J., Pringle, J. R., and Reid, B. J. (1974). Genetic control of the cell division cycle in yeast. Science 183, 46-51.

Herskowitz, I. (1965). Genetics, Second Edition (Boston: Little, Brown, \& Co.).

Herskowitz, l., and Jensen. R. E. (1991). Putting the HO gene to work: practical uses for mating-type switching. Meth. Enzymol. 194, 132146.

Hughes, A., Fukui, Y., and Yamamolo, M. (1990). Homologous activators of ras in fission and budding yeast. Nature 344, 355-357.

Hutter, K. J., and Eipel, H. E. (1978). Flow cytometric determinations of cellular substances in algae, bacteria, moulds, and yeasts. Antonie van Leeuwenhoek 44, 269-282.

Ito, H., Fukuda, Y., Murata, K., and Kimura, A. (1983). Transformation of intact yeast cells treated with alkali cations. J. Bacteriol. 153, 163168.

Johnson, D., and Pringle, J. (1990). Molecular characterization of CDC42, a gene involved in the development of cell polarity. J. Cell Biol. 111, 143-152.

Jones, S., Vignais, M. L., and Broach, J. R. (1991). The CDC25 protein of Saccharomyces cerevisiae promotes exchange of guanine nucleotides bound to Ras. Mol. Cell. Biol. 11, 2647-2655.

Kilmartin, J., and Adams, A. (1984). Structural rearrangements of tubulin and actin during the cell cycle of the yeast Saccharomyces. J. Cell Biol. 98, 922-933.

Kilmartin, J. V., Wright, B., and Milstein, C. (1982). Rat monoclonal antitubulin antibodies derived by using a new nonsecreting rat cell line. J. Cell Biol. 93, 576-582.

Levitzki, A. (1990). GTP-GDP exchange proteins. Science 248, 794.

Lillie, S. H., and Pringle, J. R. (1980). Reserve carbohydrate metabolism in Saccharomyces cerevisiae: responses to nutrient limitation. J. Bacteriol. 143, 1384-1394.
Meeks-Wagner, D., and Hartwell, L. H. (1986). Normal stoichiometry of histone dimer sets is necessary for high fidelity of mitotic chromosome transmission. Cell 44, 43-52.

Novick, P., and Botstein, D. (198b). Phenotypic analysis of temperature-sensitive yeast actin mutants. Cell 40, 405-416.

Powers, S., O'Neill, K., and Wigler, M. (1989). Dominant yeast and mammalian RAS mutants that interfere with the CDC25-dependent activation of wild-type RAS in Saccharomyces cerevisiae. Mol. Cell. Biol. 9, 390-395.

Powers, S., Gonzalez, E., Christensen, T., Cubert, J., and Broek, D. (1991). Functional cloning of BUD5, a CDC25-related gene from $S$ cerevisiae that can suppress a dominant-negative RAS2 mutant. Cell, this issue.

Pringle, J. R., and Hartwell, L. H. (1981). The Saccharomyces cerevisiae cell cycle. In The Molecular Biology of the Yeast Saccharomyces Life Cycle and Inheritance, J. N. Strathern, E. W. Jones, and J. R. Broach, eds. (Cold Spring Harbor, New York: Cold Spring Harbor Laboratory), pp. 97-142

Pringle, J. R., and Mor, J.-R. (1975). Methods for monitoring the growth of yeast cultures and for dealing with the clumping problem. Meth. Cell Biol. 11, 131-168.

Pringle, J. R., Preston, R. A., Adams, A. E. M., Stearns, T., Drubin, D. G., Haarer, B. K., and Jones, E. W. (1989). Fluorescence microscopy methods for yeast. Meth. Cell Biol. 31, 357-435.

Rose, M. D. (1987). Isolation of genes by complementation in yeast. Meth. Enzymol. 152, 481-502.

Rose, M. D., Novick, P., Thomas, J. H., Botstein, D., and Fink, G. R. (1987). A Saccharomyces cerevisiae genomic plasmid bank based on a centromere-containing shuttle vector. Gene $60,237-243$.

Rothstein, R. J. (1983). One-step gene disruption in yeast. Meth. Enzy mol. 101, 202-209.

Sanger, F., Nicklen, S., and Coulson, A. R. (1977). DNA sequencing with chain-terminating inhibitors. Proc. Nat1. Acad. Sci. USA 74, 54635467.

Sherman, F., Fink, G. R., and Hicks, J. B. (1982). Methods in Yeast Genetics (Cold Spring Harbor, New York: Cold Spring Harbor Laboratory).

Sloat, B. F., and Pringle, J. R. (1978). A mutant of yeast defective in cellular morphogenesis. Science 200, 1171-1173.

Sloat, B., Adams, A., and Pringle, J. (1981). Roles of the CDC24 gene product in cellular morphogenesis during the Saccharomyces cerevisiae cell cycle. J. Cell Biol. 89, 395-405.

Sprague, G. F., Jr. (1991). Assay of yeast mating reaction. Meth. Enzymol. 194, 77-93.

Strathern, J. N., Hicks, J., and Herskowitz, I. (1981). Control of cell type in yeast by the mating type locus: the $\alpha 1-\alpha 2$ hypothesis. J. Mol. Biol. 147, 357-372.

Tanaka, K., Nakafuku, M., Satoh, T., Marshall, M. S., Gibbs, J. B Matsumoto, K., Kaziro, Y., and Toh-e, A. (1990). S. cerevisiae genes IRA1 and IRA2 encode proteins that may be functionally equivalent to mammalian ras GTPase activating protein. Cell 60, 803-807.

Tatchell, K., Nasmyth, K. A., Hall, B. D., Astell, C., and Smith, M. (1981). In vitro mutation analysis of the mating-type locus in yeast. Cell $27,25-35$.

Trahey, M., and McCormick, F. (1987). A cytoplasmic protein stimulates normal N-ras p21 GTPase, but does not affect oncogenic mutants. Science 238, 542-545.

Wickner, R. B., Koh, T. J., Crowley, J. C., O'Neil, J., and Kaback, D. B. (1987). Molecular cloning of chromosome I DNA from Saccharomyces cerevisiae: isolation of the MAK16 gene and analysis of an adjacent essential for growth at low temperature. Yeast 3, 51-57.

Wilkinson, L. E., and Pringle, J. R. (1974). Transient G1 arrest of Saccharomyces cerevisiae of mating type $\alpha$ by a factor produced by cells of mating type a. Exp. Cell Res. 89, 175-187.

\section{GenBank Accession Number}

The accession number for the BUD5 nucleotide sequence reported in this paper is $\mathrm{M} 63552$. 